\title{
Does the Age of Packed Red Blood Cells, Donor Sex or Sex Mismatch Affect the Sublingual Microcirculation in Critically III Intensive Care Unit Patients? - A Secondary Interpretation of a Retrospective Analysis
}

\section{Demian Knobel}

Universitatsspital Basel https://orcid.org/0000-0002-9320-8075

\section{Jonas Scheuzger}

Universitätsspital Basel: Universitatsspital Basel

Andreas Buser

Universitätsspital Basel: Universitatsspital Basel

Alexa Hollinger

Universitätsspital Basel: Universitatsspital Basel

Caroline E. Gebhard

Universitätsspital Basel: Universitatsspital Basel

Rita Achermann

Universitätsspital Basel: Universitatsspital Basel

Anna Zaiser

Universitätsspital Basel: Universitatsspital Basel

\section{Yann Bovey}

Universitätsspital Basel: Universitatsspital Basel

Jasprit Singh

Universitätsspital Basel: Universitatsspital Basel

Martin Siegemund ( $\nabla$ Martin.Siegemund@usb.ch )

University Hospital Basel https://orcid.org/0000-0002-2013-4140

\section{Research}

Keywords: Storage lesions, transfusion

Posted Date: July 12th, 2021

DOI: https://doi.org/10.21203/rs.3.rs-665862/v1 
License: (c) (i) This work is licensed under a Creative Commons Attribution 4.0 International License. Read Full License 


\section{Abstract}

\section{Background}

In vitro studies have thoroughly documented the impact of storage lesions in packed red blood cells (pRBC) on erythrocyte oxygen carrying capacity due to older age of blood products. While studies have examined the effect of pRBC age on patient outcome, only few data exist on the microcirculation, their primary site of action.

\section{Methods}

In this secondary analysis, we examined the relationship between the age of pRBC and changes of microcirculatory flow (MCF) in 54 patients. Data from the Basel Bedside assessment Microcirculation Transfusion Limit study ( $\left.\mathrm{Ba}^{2} \mathrm{MiTraL}\right)$, investigating the effects of one $\mathrm{pRBC}$ on the sublingual MCF provided the basis of this study.

\section{Results}

Mean change from pre-to post-transfusion proportion of perfused vessels ( $\triangle \mathrm{PPV}$ ) was $+8.8 \%$ (IQR: $-0.5-$ 22.5), 5.5\% (IQR: $0.1-10.1$ ), and +4.7\% (IQR: $-2.1-6.5$ ) after transfusion of fresh ( $\leq 14$ days old), medium ( 15 to 34 days old), and old ( $\geq 35$ days old) pRBC, respectively. Values for the microcirculatory flow index (MFI) were +0.22 (IQR: $-0.1-0.6$ ), +0.22 (IQR: $0.0-0.3$ ), and +0.06 (IQR: $-0.1-0.3$ ) for the fresh, medium, and old pRBC age groups, respectively.

Lower $\triangle \mathrm{PPV}$ and transfusion of older blood were correlated with a higher Sequential Organ Failure Assessment (SOFA) score of patients upon admission to the intensive care unit (ICU) $(p=0.01)$. However, regression models showed no overall significant correlation between $\mathrm{pRBC}$ age and $\triangle \mathrm{PPV}(p=0.2)$. No correlation between donor's sex or a mismatch between donor and recipient sex was found.

\section{Conclusion}

We detected no significant correlation between age of PRBC and change in MCF between pre- and posttransfusion among all investigated patients. However, in patients with a higher SOFA score upon ICU admission, there might be a negative effect on the proportion of perfused microcirculatory vessels after transfusion of older blood.

\section{Background}

Transfusion of packed red blood cells (pRBC) to correct anaemia is a frequent therapy in intensive care unit (ICU) patients and is used against blood loss as well as to improve oxygen delivery [1]. Although considered safe and potentially lifesaving, the risk of adverse transfusion reactions should be acknowledged. 
pRBC may develop so-called storage lesions during their shelf life. The oxygen-carrying capacity of pRBC is lowered by the reduction of adenosine triphosphate (ATP) and 2,3-diphosphoglycerate, membrane phospholipid peroxidation and vesiculation, protein oxidation, loss of deformability, and increased osmotic fragility [2-4]. This leads to increased haemolysis and the occurrence of cell-free haemoglobin [5], which may in turn cause vasoconstriction due to scavenging of nitric oxide (NO) by free haemoglobin $[5,6]$. Overall, this may reduce perfusion of the microcirculation [7], resulting in worsened tissue oxygenation [3].

Nowadays, microcirculatory flow (MCF) can be measured sublingually at the bedside using handheld microscopes $[8,9]$, facilitating easy detection of the effects of pRBC on MCF and indirectly on organ perfusion. Thus, measuring MCF could be a valuable extension to guide transfusion decisions [10].

In order to evaluate the role of pRBC on sublingual microcirculation at different haemoglobin transfusion thresholds, we conducted a prospective observational trial [10], in which Scheuzger et al. showed that the influence of $\mathrm{pRBC}$ on microcirculatory vessel perfusion was independent from the initial haemoglobin $\mathrm{Hb})$ level. MCF improved in approximately one third of all patients after transfusion of pRBC. This improvement was inversely correlated with pre-transfusion values. Patients with an initial proportion of perfused vessels (PPV) of $88 \%$ or lower improved their MCF after transfusion of one pRBC.

In this secondary analysis of this prospective cohort, we aim to test the hypothesis that storage lesions of older pRBC may negatively impact MCF.

\section{Methods}

This retrospective single-centre analysis is based on the observational study of Scheuzger et al [10] (see section Protocol below). More details to patient-cohort and methods are listed in this previous trial, which was approved by the local ethics committee (Ethics Committee of Northwest and Central Switzerland, EKNZ, project ID: 2017 - 01190).

\section{Patients}

Patients were recruited from the intensive care unit (ICU) of the University Hospital Basel, Switzerland, between September 2017 and September 2018. Upon discretion of the treating intensivist sixty-four patients with anaemia $(\mathrm{Hb}<90 \mathrm{~g} / \mathrm{l})$ in sepsis, after trauma, or with postoperative bleeding receiving pRBC were included. Transfusion threshold (TTH) was set at $75 \mathrm{~g} / \mathrm{l}$ or $90 \mathrm{~g} / \mathrm{l}$ in patients with cardiac comorbidities.

Patients aged $<18$ years and those requiring mechanical assist devices, presenting with orofacial trauma, active oral bleeding, or any other condition complicating sublingual microcirculatory measurement were excluded.

\section{Protocol}


In the $\mathrm{Ba}^{2} \mathrm{MiTraL}$ study, sublingual microcirculatory measurements were performed within 1 hour before (T1) and within 1 hour after (T2) transfusion of one unit (300 ml) of a leukocyte-depleted RBC. At each time point, the best three measurements were used for the analysis. For all measurements CytoCam( (Braedius, Netherlands) based on incident dark-field illumination technology was used. The SOFA score was recorded at $\mathrm{T} 1$.

In the present analysis, we completed the dataset for the 64 patients of the $\mathrm{Ba}^{2} \mathrm{MiTraL}$ trial with information concerning the age (days) of the pRBC, sex and blood group of donor. We excluded ten patients due to rapid transfusion without follow-up measurement or missing registration numbers of the pRBC. For the evaluation of the effect of sex on chance in transfusion values, only 43 cases were included due to missing information on the donor's sex.

\section{MCF assessment}

Several possible parameters are available to describe the quality of the MCF. The two most important parameters, the proportion of perfused vessels (PPV) and the microvascular flow index (MFI), were used in our analysis [11, 12].

\section{Assessment of transfused pRBC}

For graphical representation of the change in PPV $(\triangle P P V)$ after transfusion, age of blood was divided into 3 groups: fresh (8 to 14 days), medium (15 to 34 days), and old blood (35 to 48 days): As relevant changes in erythrocytes have been reported to occur after two weeks [7], we designated $\leq 14$ days as the first cut-off. For relatively old blood, the threshold was set at five weeks ( $\geq 35$ days) in accordance with thresholds used in previous studies $[7,13-16]$.

In our hospital, pRBC are suspended in two different storage solutions: saline-adenine-glucose-mannitol (SAG-M) and phosphate-adenine-glucose-guanosine-saline-mannitol (PAGGS-M:), which allow a storage time of $\leq 42$ days and $\leq 49$ days, respectively [17].

\section{Statistical analysis}

$\triangle \mathrm{MFI}$ and $\triangle \mathrm{PPV}$ were calculated by taking the difference between the mean of the three measurements from pre- and post-transfusion values of MFI or PPV, respectively. For the assessment of intermeasurement variance, ANOVA was used. The correlation between the change in $\triangle \mathrm{PPV}$ and $\triangle \mathrm{MFI}$ and the age of the PRBC was modelled using linear regression.

To investigate whether the association between blood age and $\triangle \mathrm{PPV}$ and $\triangle \mathrm{MFI}$ correlates with the Sequential Organ Failure Assessment (SOFA) score, we divided the patients into a group of critically ill patients with a SOFA score $\geq 10(n=18)$ and patients with a SOFA score $<10(n=36)$. This variable was included as the covariate in the linear regression model as an interaction term with pRBC age.

In addition, $\mathrm{pRBC}$ donor's sex was set in relation to the $\triangle \mathrm{PPV}$. In particular, we wanted to examine whether there was a correlation of those delta values in donor-recipient sex-mismatch. Regression models were 
used to calculate the influence of blood age on the $\triangle \mathrm{PPV}$ for the two groups.

For all tests, alpha error $(p<0.05)$ was considered significant. Calculations were performed using $\mathrm{R}$ Studio@, version 3.6.1 (2019-07-05; R Studio@), Inc., Boston, MA, USA, 2009-2020). For non-normally distributed values, data are presented as median and interquartile range (IQR), otherwise as mean and standard deviation (SD).

\section{Results}

Baseline characteristics are shown in Table 1. Transfusion figures regarding blood groups and donorrecipient sex-mismatches are listed in the Appendix (Appendix Table 1).

Table 1

Patient characteristics

\begin{tabular}{|lllll|}
\hline Characteristic & $\begin{array}{l}\text { Total } \\
(\boldsymbol{n}=\mathbf{5 4})\end{array}$ & $\begin{array}{l}\text { Fresh } \\
(\boldsymbol{n}=9)\end{array}$ & $\begin{array}{l}\text { Medium } \\
(\boldsymbol{n}=\mathbf{2 7})\end{array}$ & $\begin{array}{l}\text { Old } \\
(\boldsymbol{n}=18)\end{array}$ \\
\hline Male, $n$ (\%) & $30(55.6)$ & $3(33.3)$ & $15(55.6)$ & $12(66.7)$ \\
\hline Mean age, SD (years) & $64.9(15.2)$ & $61.2(15.0)$ & $69.0(14.7)$ & $60.6(15.2)$ \\
\hline SOFA score (points) & $7(3-11)$ & $10(3-12)$ & $7(4-11)$ & $5(3-7)$ \\
\hline Septic shock, $n(\%)$ & $11(20.4)$ & $2(22.2)$ & $6(22.2)$ & $3(16.7)$ \\
\hline Cardiogenic shock, $n(\%)$ & $16(29.6)$ & $3(33.3)$ & $9(33.3)$ & $4(22.2)$ \\
\hline Haemorrhagic shock, $n(\%)$ & $18(33.3)$ & $1(11.1)$ & $7(25.9)$ & $10(55.6)$ \\
\hline Mechanical ventilation, $n(\%)$ & $24(44.4)$ & $5(55.6)$ & $11(40.7)$ & $8(44.4)$ \\
\hline Hb before pRBC (g/l) & $74.5(72-79)$ & $79(72-85)$ & $74(72-78)$ & $74.5(73-78)$ \\
\hline Blood type donor, 0, $n(\%)$ & $20(37)$ & $4(7)$ & $10(19)$ & $6(11)$ \\
\hline Length of ICU stay (days) & $5(2-12)$ & $8(4-16)$ & $4(1.5-11)$ & $5(2.3-11)$ \\
\hline Death in ICU, $n$ (\%) & $5(9.3)$ & $0(0)$ & $3(11.1)$ & $2(11.1)$ \\
\hline
\end{tabular}

$S D$ standard deviation; SOFA sequential organ failure assessment; $H b$ haemoglobin; $p R B C$ packed red blood cells; ICU intensive care unit

If not mentioned differently, all values above are medians with corresponding interquartile range (IQR)

Thirty patients were male (55.6\%), and mean age at time of transfusion was 64.9 years $(S D=15.2)$. Median time of processing and storage of pRBC from donation to transfusion was 28.5 days. Maximum time of storage was 42 days, except for one patient who received 48 day-old pRBC, which was suspended in PAGGS-M. 
Median change from pre- to post-transfusion for PPV was + 3.45\% (IQR: -1.6-10.7), and mean change for MFI was $+0.17(S D=0.38)$. The variance in measurements within subjects were $18.6 \%$ for PPV pretransfusion, $23.2 \%$ for PPV post-transfusion, $10.8 \%$ for MFI pre-transfusion and $19.5 \%$ for MFI posttransfusion. Table 2 displays the results of the regression analysis for the overall correlation between the change in PPV from pre- to post-transfusion ( $\triangle P P V)$ and the age of the PRBC, both of which were not statistically significant $(p=0.29)$.

Table 2

Regression model of $\triangle \mathrm{PPV}$ and age of pRBC

\begin{tabular}{|llll|}
\hline Co-variable & Estimate & Confidence interval & P-value \\
\hline Intercept $\triangle \mathrm{PPV}$ & 10.41 & $(1.02-19.81)$ & 0.03 \\
\hline Age of pRBC & -0.17 & $(-0.49-0.15)$ & 0.29 \\
\hline Adjusted R-squared: $1.4 \% ; n=54$ & & \\
\hline $\begin{array}{l}\Delta \text { Difference between pre- and post-transfusion measurement; } P P V \text { proportion of perfused vessels; } \\
p R B C \text { packed red blood cells }\end{array}$ & & \\
\hline
\end{tabular}

Linear regression model of $\triangle \mathrm{PPV}$ in percent and the age of pRBC (in days) is shown in Fig. 1. Changes in PPV were lower in patients who were administered older PRBC. As shown in the regression analysis, no significant effect was observed between $\triangle P P V$ and age of pRBC.

Figure 2A shows a boxplot for $\triangle \mathrm{PPV}$ by $\mathrm{pRBC}$ age group with similar values regarding age of transfused pRBC. Patients with a high pre-transfusion PPV level were overrepresented by chance in the older pRBC age group. Therefore, it is less likely that the PPV level truly increases after administration of pRBC (Fig. 2B).

SOFA score was pathologic ( $\geq 2$ points) in 46 cases (median $=7$ ). With the threshold of ten points for severe cases, 18 patients (33.3\%) were grouped above and 36 (66.7\%) below the limit. Table 3 shows the results of the regression analysis including co-variables age of $\mathrm{pRBC}$, the SOFA score as well as an interaction between these two variables $(p=0.01)$. Figure 3 shows the results of this linear regression model for patients with low and high SOFA score for the outcome $\triangle \mathrm{PPV}$ and $\triangle \mathrm{MFI}$. Although no difference can be detected in patients with low SOFA score, there is a trend to lower $\triangle \mathrm{PPV}$ and $\triangle \mathrm{MFI}$ in critically ill patients receiving older pRBC. 
Table 3

Results of regression model, including the interaction of the co-variable SOFA score

\begin{tabular}{|llll|}
\hline Co-variable & Estimate & Confidence interval & p-value \\
\hline Intercept $\triangle \mathrm{PPV}$ & -2.15 & $(-19.6-15.3)$ & 0.81 \\
\hline Age of pRBC & 0.41 & $(-0.16-0.98)$ & 0.16 \\
\hline SOFA score, high & 1.89 & $(-0.06-3.85)$ & 0.06 \\
\hline Interaction SOFA score and age of pRBC & -0.09 & $(-0.16-0.02)$ & 0.01 \\
\hline Adjusted R-squared: $11.2 \% ; n=54$ & & & \\
\hline $\begin{array}{l}\text { SOFA Sequential Organ Failure Assessment; } \Delta \text { difference between pre- and post-transfusion } \\
\text { measurement; } P P V \text { proportion of perfused vessels; } p R B C \text { packed red blood cells }\end{array}$ & \\
\hline
\end{tabular}

Values for $\triangle \mathrm{PPV}$ and $\triangle \mathrm{MFI}$ regarding the grouping with SOFA score and blood age are listed in Table 4.

The relationship between donor's sex and $\triangle \mathrm{PPV}$ and $\triangle \mathrm{MFI}$ (see Appendix Table 2) was not significant (for $\Delta \mathrm{PPV}, p=0.7$; for $\Delta \mathrm{MFI}, p=0.3$ ). In addition, no correlation was seen when compared to donorrecipient sex-mismatch. A mismatch was detected in 26 cases (60.47\%). Differences between matches and mismatches were not significant for $\Delta \mathrm{PPV}(p=0.5)$ or for $\Delta \mathrm{MFI}(p=0.6)$.

Table 4

Age of pRBC and effects on MCF regarding SOFA score and blood-age groups

SOFA-score $<10$

$\begin{array}{lllllll}\text { Age group } & \text { Fresh } & \text { Medium } & \text { Old } & \text { Fresh } & \text { Medium } & \text { Old } \\ n \text { (of total } & 3 & 18 & 15 & 6 & 9 & 3\end{array}$

54)

Age of $p R B C$

(d)

$\triangle \mathrm{PPV}(\%)$

$\Delta \mathrm{MFI}(\mathrm{SD})$

$10(9.5-$

12)

27 (22.8-

29.8)

39 (37-

40.5)

$3.3(0.3-$

11.4)

$3.1(-2-9)$

11)

$-0.03(0.6)$

$0.23(0.4)$

$0.09(0.3)$

$0.35(0.4)$

$11(9.5-$

11.8)

$25(21-$

30)

36 (35.5-

37)

12.9 (2.9-

$5(-0.2-$

7.8)

$-2.1(-5.9-$

1.4)

$0.19(0.3) \quad-0.1(0.3)$

Fresh (< 14 days old), medium ( 15 to 34 days old) or relatively old blood ( $>35$ days old))

SOFA Sequential Organ Failure Assessment; $\Delta$ difference between pre- and post-transfusion measurement; $P P V$ proportion of perfused vessels; $M F /$ microvascular flow index; $p R B C$ packed red blood cells; $S D$ standard deviation

\section{Discussion}


Patients receiving blood aged 35 to 48 days did not have a significantly lower $\triangle P P V$ after transfusion of pRBC. However, in severely critically ill patients (i.e., SOFA score $\geq 10$ ) PPV increased less when older versus fresh $\mathrm{pRBC}$ was transfused. In this group of patients, age of pRBC may be of importance, whereby severely ill ICU patients with poor MCF may profit from shorter stored blood. Two possible explanations could be 1) the pre-existing impairment of the patient's own erythrocytes due to critical illness, and 2) impaired erythrocyte-to-capillary interaction [18]. Therefore, administered pRBC containing storage lesions might not enter the already altered microcirculation and might not bring this group of patients the same positive effects as fresh pRBC. These findings jeopardize today's arbitrary haemoglobin-derived transfusion thresholds where neither MCF impairment or severity of illness nor the age of the transfused blood is taken into account.

Microcirculatory blood vessels (i.e., arterioles, capillaries, and venules) are those vessels with a diameter be $<100 \mu \mathrm{m}$. Homogenous MCF is crucial for tissue oxygenation [19]. Thus, understanding the role of MCF and implementation of corresponding measurements and study results in the treatment of patients is of great importance but confirmatory data from prospective trials are lacking. In septic patients, for example, persistent MCF alteration correlates with adverse outcome [11, 20-23], thus, warranting treatment [19].

For tissue and microcirculatory perfusion, blood flow is of greater importance than blood pressure [24]. In a prospective study of 20 septic shock patients, MCF alterations could not be improved after elevation of mean arterial pressure (MAP) with norepinephrine [25]. In the second consensus on the assessment of sublingual microcirculation [26], the authors listed heterogeneous blood flow, haemodilution, and stagnant microcirculatory flow due to arterial vasoconstriction or oedema with prolonged oxygen diffusion distances as reasons for discrepant macro- and microcirculatory flow patterns.

Two previous studies examining the relationship between the age of pRBC and the MCF produced divergent findings. Weinberg and colleagues reported decreased perfused capillary density (PCD) after transfusion of older pRBC with consecutive changes in regional microvascular perfusion in a cohort of 93 patients [27]. In contrast, Yürük and colleagues detected no such effects in their 20 patient cohort [28], thereby, concluding that although the impact of storage lesions on haemorheology is well-known, but its clinical relevance remains unclear.

While the average age of pRBC at the time of transfusion is between 16-21 days [1,29], many countries allow a storage time for up to 42 days [30]. Of note, a decrease in oxygen-delivering capacity was seen after storage of five to six weeks (35-42 days) [7].

With a median storage age of 28.5 days, age of pRBC used in our study was even higher than both our hospital average (mean $=22.9$ days) and the international average described above. In order not to waste any blood products, it is a common practice to transfuse the oldest available pRBC first with a minimum time to process a unit of pRBC being two days [17]. 
Overall, there is a slight tendency to a less pronounced increase of blood flow in the microcirculation after transfusion of older blood. However, our data show no statistical significance in the correlation between the age of pRBC up to a maximum storage of 49 days and $\triangle M C F$ values. Unequal distribution of data may explain the difference to the previously mentioned inverse correlation with the SOFA subgroups.

Several authors have reported no difference in MCF in studies comparing transfusion of younger (7-20 days old) to older (21 to 42 days old) pRBC [4, 13-15, 28, 31]. Our own comparisons of fresh, medium, and old blood also did not detect a significant difference between MCF and pRBC age. However, these numbers do not respect severity of illness.

A more clinical approach was used in several large randomized controlled trials. Patient outcome, such as mortality, was investigated in the ABLE [32], RECESS [33] or TRANSFUSE [34] trials. Results of these studies as well as of other trials were summarized in a Cochrane analysis in 2018 [35], and revealed no clear difference in the risk of death after transfusion of blood closer to the expiration date in adults. Based on these findings, transfusion of relatively old blood was considered safe [35]. Nevertheless, these studies also failed to consider the severity of illness. Moreover, mass transfusions were not examined. Studies on the infusion of large volumes of pRBC are thus necessary to shed light on the relevance of storage lesions [36].

Mismatch in sex of donor and recipient of pRBC is described in the literature as a possible factor influencing the outcome of transfusion [37]. We could not detect a benefit in matching pRBC to the recipient's sex in terms of MCF and also did not find a negative impact of mismatch on flow in capillaries. In addition, no significant differences of donor's sex and change in MCF could be detected, possibly also due to the small sample size of our study.

Finally, so-called storage lesions due to prolonged storage are well described and understood in in-vitro as well as in in-vivo animal models, but the clinical significance remains unclear $[7,28,38,39]$. Therefore, the findings of this investigation can only be seen as a jigsaw piece in the field of microcirculation studies with considerable uncertainty. The growing importance of individualized patient treatment in medicine supports bedside measurement of perfusion within the smallest vessels in real-time (MCF), thus serving as an indirect predictor of erythrocyte flow and oxygen delivery to the organs $[26,40]$.

Our study has several limitations. First, as a retrospective analysis, collection of data about transfused pRBCs was difficult due to missing values in patient charts. Second, the sample size was not powered for the presented research question, and data were not distributed equally due to the standard practice of blood banks to transfuse older pRBCs first. This explains the underrepresentation of fresh blood in this trial. Third, variability of measurements was high. Here, an automated software analysis could help in the future. In addition, distinctions between different groups may be larger with transfusion of fresh blood being even younger than eight days.

\section{Conclusion}


Our data support findings that transfusion of older blood, up to 42 days old, does not seem to affect microcirculatory flow. This is in accordance with existing research about microcirculatory changes of blood transfusion and large randomized trials on the outcome of blood transfusions. The trend to lower PPV and MFI in patients with SOFA score > 10 suggest further research on the influence of pRBC transfusions age on the microcirculation in dependence of critical illness severity. Further, we suggest the use of regular measurements of microcirculatory parameters (e.g. capillary refill time or MCF) to adapt transfusions to individual patient requirements rather than simply following arbitrary thresholds.

\section{Abbreviations}

$\mathrm{Ba}^{2} \mathrm{MiTraL}$

Basel Bedside assessment Microcirculation Transfusion Limit study; Cl:Confidence interval; $\Delta$ :Delta; ICU:Intensive care unit; $\mathrm{Hb}$ :Haemoglobin; MCF:Microcirculatory flow; MFI:Microvascular flow index; PAGGS-M:Phosphate-adenine-glucose-guanosine-saline-mannitol; PPV:Proportion of perfused vessels; pRBC:Packed red blood cells; SAGM:Saline-adenine-glucose-mannitol; SD:Standard deviation; SOFA:Sequential Organ Failure Assessment

\section{Declarations}

\section{Ethics approval and consent to participate}

The cantonal ethics committee (Ethics committee of Northwest and Central Switzerland (EKNZ)) has approved the initial study (Reference number: EKNZ 2017-01190). Written consent and consent for publication were obtained for all participating patients or their next of kin as part of the $\mathrm{Ba}^{2} \mathrm{MiTraL}-$ trial. No further patient-measurements were necessary for this secondary analysis.

\section{Consent for publication}

Not applicable

\section{Availability of data and materials}

The data that support the findings of this study are available from the corresponding author upon reasonable request

\section{Competing interests}

The authors declare that they have no competing interests.

\section{Funding}

JS received a research grant "Young Talents in Clinical Research" from the "Goldschmidt \& Jacobson Foundation" from the University of Basel, Switzerland. The CytoCam ${ }^{\odot}$ device was purchased in the 
context of another trial and was funded by the "Gottfried und Julia Bangerter-Rhyner-Stiftung". CEG was supported by grants from the Research Foundation for Anesthesiology and Intensive Care Medicine, University Hospital Basel, the Research Fund of the University of Basel, and the Swiss National Science Foundation (SNSF).

\section{Authors' contributions}

JS and MS designed the initial $\mathrm{Ba}^{2} \mathrm{MiTraL}$-trial. DK completed the dataset with $\mathrm{pRBC}$ parameters with the help of AB. DK and RA performed the statistical analysis. DK, MS, and JS drafted the report.

\section{Acknowledgements}

We thank Allison Dwileski, Anesthesiology, University Hospital Basel, for the editorial support.

\section{References}

1. Corwin HL, Gettinger A, Pearl RG, Fink MP, Levy MM, Abraham E, et al. The CRIT Study: Anemia and blood transfusion in the critically ill-current clinical practice in the United States. Crit Care Med. 2004;32:39-52. doi:10.1097/01.CCM.0000104112.34142.79.

2. Card RT, Mohandas N, Perkins HA, Shohet SB. Deformability of stored red blood cells. Relationship to degree of packing. Transfusion. 1982;22:96-101. doi:10.1046/j.1537-2995.1982.22282177134.x.

3. Tinmouth A, Fergusson D, Yee IC, Hébert PC. Clinical consequences of red cell storage in the critically ill. Transfusion. 2006;46:2014-27. doi:10.1111/j.1537-2995.2006.01026.x.

4. Damiani E, Adrario E, Luchetti MM, Scorcella C, Carsetti A, Mininno N, et al. Plasma free hemoglobin and microcirculatory response to fresh or old blood transfusions in sepsis. PLOS ONE. 2015;10:e0122655. doi:10.1371/journal.pone.0122655.

5. Donadee C, Raat NJH, Kanias T, Tejero J, Lee JS, Kelley EE, et al. Nitric oxide scavenging by red blood cell microparticles and cell-free hemoglobin as a mechanism for the red cell storage lesion. Circulation. 2011;124:465-76. doi:10.1161/CIRCULATIONAHA.110.008698.

6. Reynolds JD, Ahearn GS, Angelo M, Zhang J, Cobb F, Stamler JS. S-nitrosohemoglobin deficiency: a mechanism for loss of physiological activity in banked blood. Proc Natl Acad Sci U S A. 2007;104:17058-62. doi:10.1073/pnas.0707958104.

7. Raat NJ, Verhoeven AJ, Mik EG, Gouwerok CW, Verhaar R, Goedhart PT, et al. The effect of storage time of human red cells on intestinal microcirculatory oxygenation in a rat isovolemic exchange model. Crit Care Med. 2005;33:39-45. doi:10.1097/01.CCM.0000150655.75519.02. discussion 2389.

8. Ocak I, Kara A, Ince C. Monitoring microcirculation. Best Pract Res Clin Anaesthesiol. 2016;30:40718. doi:10.1016/j.bpa.2016.10.008.

9. Backer $D$ de. Is microcirculatory assessment ready for regular use in clinical practice? Curr Opin Crit Care. 2019;25:280-4. doi:10.1097/MCC.0000000000000605. 
10. Scheuzger J, Zehnder A, Meier V, Yeginsoy D, Flükiger J, Siegemund M. Sublingual microcirculation does not reflect red blood cell transfusion thresholds in the intensive care unit-a prospective observational study in the intensive care unit. Crit Care. 2020;24:18. doi:10.1186/s13054-020-2728-7.

11. Backer D de, Donadello K, Sakr Y, Ospina-Tascon G, Salgado D, Scolletta S, Vincent J-L. Microcirculatory alterations in patients with severe sepsis: impact of time of assessment and relationship with outcome. Crit Care Med. 2013;41:791-9. doi:10.1097/ccm.0b013e3182742e8b.

12. Massey MJ, Shapiro NI. A guide to human in vivo microcirculatory flow image analysis. Crit Care. 2016;20:35. doi:10.1186/s13054-016-1213-9.

13. Risbano MG, Kanias T, Triulzi D, Donadee C, Barge S, Badlam J, et al. Effects of Aged Stored Autologous Red Blood Cells on Human Endothelial Function. Am J Respir Crit Care Med. 2015;192:1223-33. doi:10.1164/rccm.201501-01450C.

14. Roberson RS, Lockhart E, Shapiro NI, Bandarenko N, McMahon TJ, Massey MJ, et al. Impact of transfusion of autologous 7-versus 42-day-old AS-3 red blood cells on tissue oxygenation and the microcirculation in healthy volunteers. Transfusion. 2012;52:2459-64. doi:10.1111/j.15372995.2012.03615.x.

15. Stowell CP, Whitman G, Granger S, Gomez H, Assmann SF, Massey MJ, et al. The impact of red blood cell storage duration on tissue oxygenation in cardiac surgery. $\mathrm{J}$ Thorac Cardiovasc Surg. 2017;153:610-9.e2. doi:10.1016/j.jtcvs.2016.11.029.

16. Ayhan B, Yuruk K, Koene S, Sahin A, Ince C, Aypar U. The effects of non-leukoreduced red blood cell transfusions on microcirculation in mixed surgical patients. Transfus Apher Sci. 2013;49:212-22. doi:10.1016/j.transci.2013.01.016.

17. Prof. Dr. med Andreas Buser. Storage time of pRBC in Basel 29.04.2020. Basel, CH.

18. Wendelbo $\varnothing$, Hervig T, Haugen 0 , Seghatchian J, Reikvam H. Microcirculation and red cell transfusion in patients with sepsis. Transfus Apher Sci. 2017;56:900-5. doi:10.1016/j.transci.2017.11.020.

19. Ince C. The microcirculation is the motor of sepsis. Crit Care. 2005;9(Suppl 4):13-9. doi:10.1186/cc3753.

20. Backer D de, Creteur J, Preiser J-C, Dubois M-J, Vincent J-L. Microvascular blood flow is altered in patients with sepsis. Am J Respir Crit Care Med. 2002;166:98-104. doi:10.1164/rccm.200109-016oc.

21. Ait-Oufella H, Bourcier S, Lehoux S, Guidet B. Microcirculatory disorders during septic shock. Curr Opin Crit Care. 2015;21:271-5. doi:10.1097/mcc.0000000000000217.

22. Sakr Y, Dubois M-J, Backer D de, Creteur J, Vincent J-L. Persistent microcirculatory alterations are associated with organ failure and death in patients with septic shock. Crit Care Med. 2004;32:182531. doi:10.1097/01.ccm.0000138558.16257.3f.

23. Doerschug KC, Delsing AS, Schmidt GA, Haynes WG. Impairments in microvascular reactivity are related to organ failure in human sepsis. Am J Physiol Heart Circ Physiol. 2007;293:H1065-71. doi:10.1152/ajpheart.01237.2006.

24. Dünser MW, Takala J, Brunauer A, Bakker J. Re-thinking resuscitation: leaving blood pressure cosmetics behind and moving forward to permissive hypotension and a tissue perfusion-based 
approach. Crit Care. 2013;17:326. doi:10.1186/cc12727.

25. Dubin A, Pozo MO, Casabella CA, Pálizas F, Murias G, Moseinco MC, et al. Increasing arterial blood pressure with norepinephrine does not improve microcirculatory blood flow: a prospective study. Crit Care. 2009;13:R92. doi:10.1186/cc7922.

26. Ince C, Boerma EC, Cecconi M, Backer D de, Shapiro NI, Duranteau J, et al. Second consensus on the assessment of sublingual microcirculation in critically ill patients: results from a task force of the European Society of Intensive Care Medicine. Intensive Care Med. 2018;44:281-99. doi:10.1007/s00134-018-5070-7.

27. Weinberg JA, MacLennan PA, Vandromme-Cusick MJ, Magnotti LJ, Kerby JD, Rue LW, et al. The deleterious effect of red blood cell storage on microvascular response to transfusion. J Trauma Acute Care Surg. 2013;75:807-12. doi:10.1097/ta.0b013e3182a74a9b.

28. Yürük K, Milstein DMJ, Bezemer R, Bartels SA, Biemond BJ, Ince C. Transfusion of banked red blood cells and the effects on hemorrheology and microvascular hemodynamics in anemic hematology outpatients. Transfusion. 2013;53:1346-52. doi:10.1111/j.1537-2995.2012.03905.x.

29. Vincent JL, Baron J-F, Reinhart K, Gattinoni L, Thijs L, Webb A, et al. Anemia and blood transfusion in critically ill patients. JAMA. 2002;288:1499-507. doi:10.1001/jama.288.12.1499.

30. D'Alessandro A, Liumbruno G, Grazzini G, Zolla L. Red blood cell storage: the story so far. Blood Transfus. 2010;8:82-8. doi:10.2450/2009.0122-09.

31. Sadaka F, Aggu-Sher R, Krause K, O'Brien J, Armbrecht ES, Taylor RW. The effect of red blood cell transfusion on tissue oxygenation and microcirculation in severe septic patients. Ann Intensive Care. 2011;1:46. doi:10.1186/2110-5820-1-46.

32. Lacroix J, Hébert PC, Fergusson DA, Tinmouth A, Cook DJ, Marshall JC, et al. Age of transfused blood in critically ill adults. N Engl J Med. 2015;372:1410-8. doi:10.1056/NEJMoa1500704.

33. Steiner ME, Ness PM, Assmann SF, Triulzi DJ, Sloan SR, Delaney M, et al. Effects of red-cell storage duration on patients undergoing cardiac surgery. N Engl J Med. 2015;372:1419-29. doi:10.1056/NEJMoa1414219.

34. Cooper DJ, McQuilten ZK, Nichol A, Ady B, Aubron C, Bailey M, et al. Age of Red Cells for Transfusion and Outcomes in Critically III Adults. N Engl J Med. 2017;377:1858-67. doi:10.1056/NEJMoa1707572.

35. Shah A, Brunskill SJ, Desborough M, Doree JR, Trivella C, Stanworth M. SJ. Transfusion of red blood cells stored for shorter versus longer duration for all conditions. Cochrane Database Syst Rev. 2018;12:CD010801. doi:10.1002/14651858.CD010801.pub3.

36. Weinberg JA, Patel RP. Red blood cell transfusion and its effect on microvascular dysfunction in shock states. Best Pract Res Clin Anaesthesiol. 2016;30:491-8. doi:10.1016/j.bpa.2016.10.005.

37. Heddle NM, Cook RJ, Liu Y, Zeller M, Barty R, Acker JP, et al. The association between blood donor sex and age and transfusion recipient mortality: an exploratory analysis. Transfusion. 2019;59:48291. doi:10.1111/trf.15011. 
38. van Bommel J, Korte D de, Lind A, Siegemund M, Trouwborst A, Verhoeven AJ, et al. The effect of the transfusion of stored RBCs on intestinal microvascular oxygenation in the rat. Transfusion. 2001;41:1515-23. doi:10.1046/j.1537-2995.2001.41121515.x.

39. van de Watering L. Red cell storage and prognosis. Vox Sang. 2011;100:36-45. doi:10.1111/j.14230410.2010.01441.x.

40. Massey MJ, Larochelle E, Najarro G, Karmacharla A, Arnold R, Trzeciak S, et al. The microcirculation image quality score: development and preliminary evaluation of a proposed approach to grading quality of image acquisition for bedside videomicroscopy. J Crit Care. 2013;28:913-7. doi:10.1016/j.jcrc.2013.06.015.

Figures

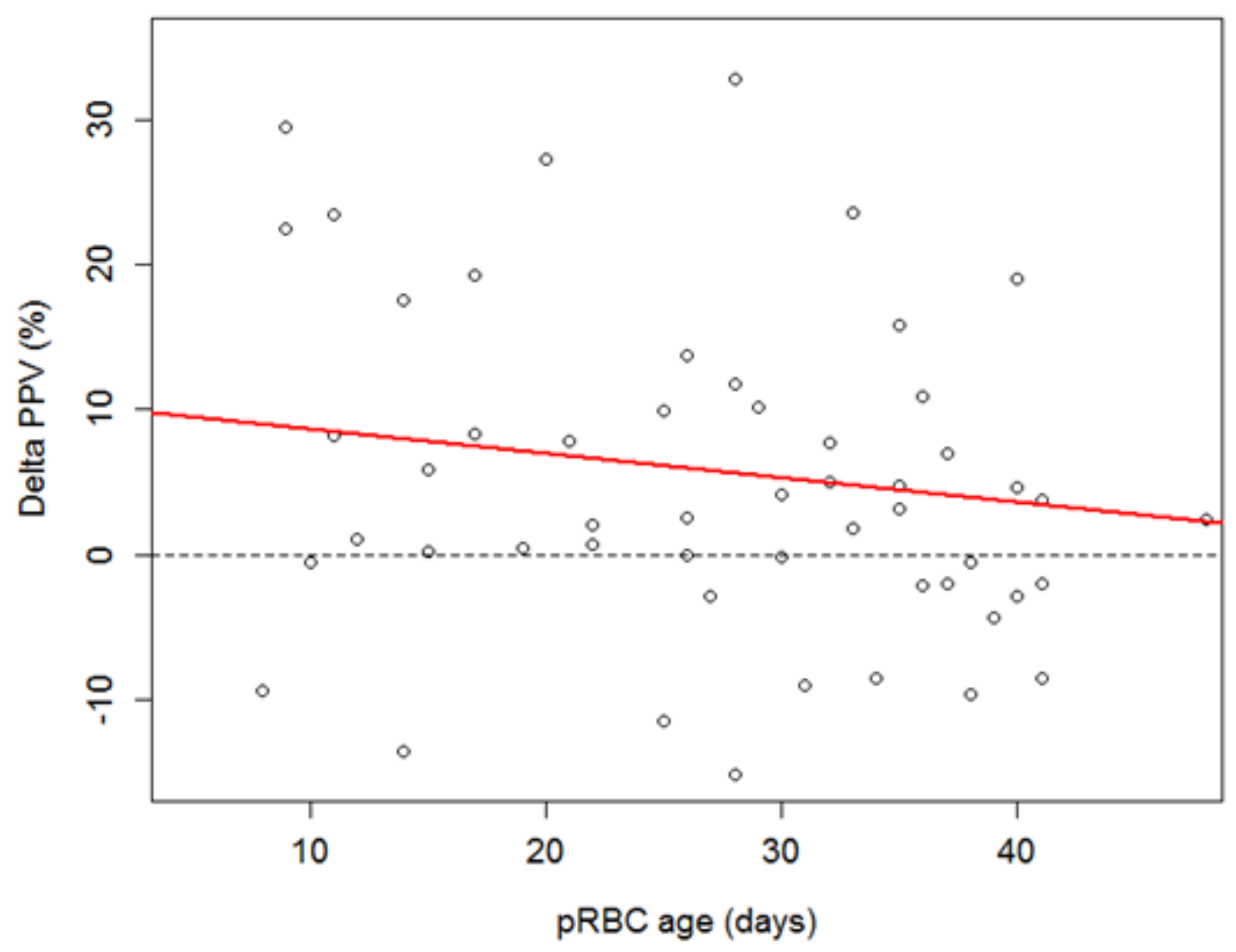

Figure 1

Linear regression model of pre-to post-transfusion proportion of perfused vessels ( $\triangle \mathrm{PPV}$ ) in percent and the age of pRBC (in days). The red line indicates the trend to a lower increase in $\triangle \mathrm{PPV}$ in older blood cell concentrates. 


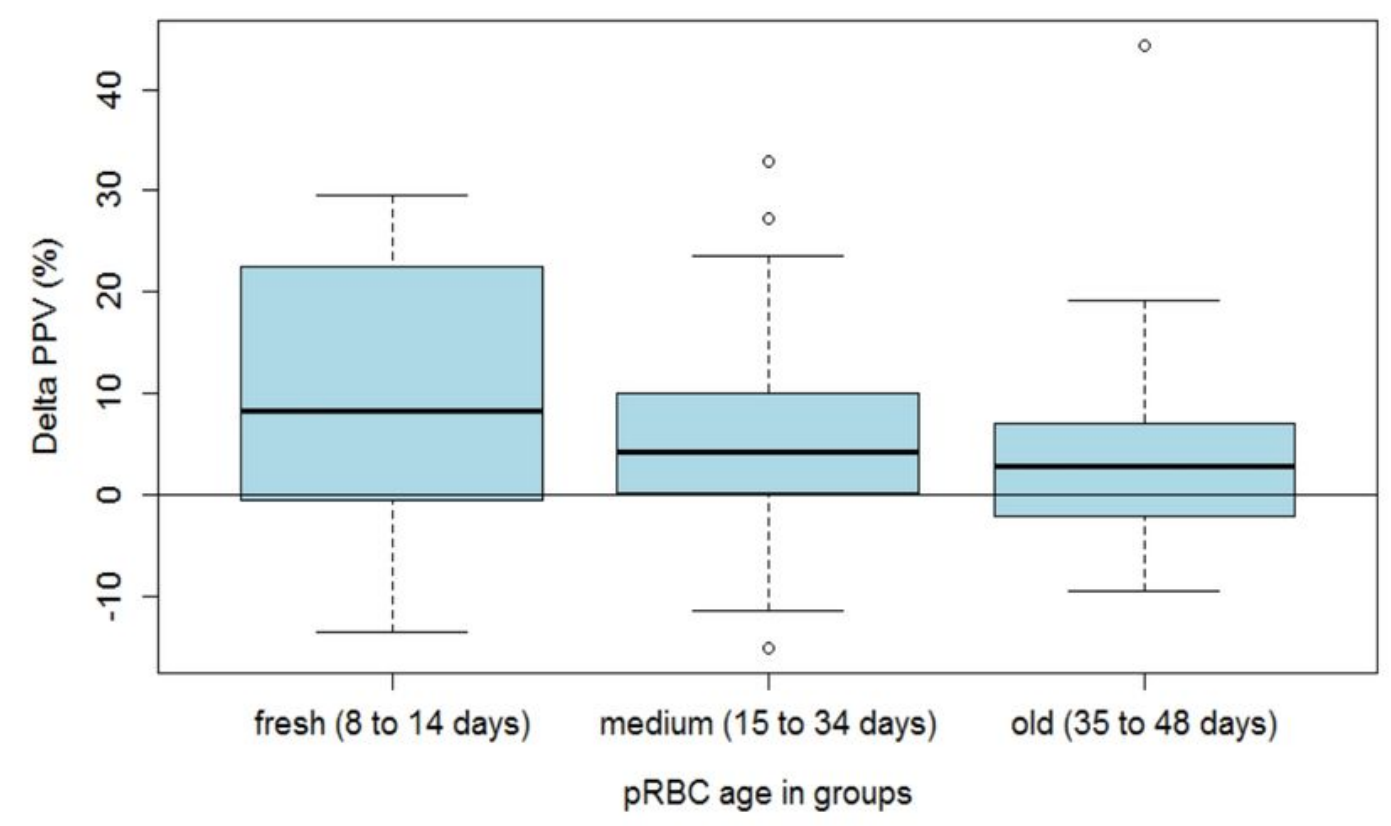

B

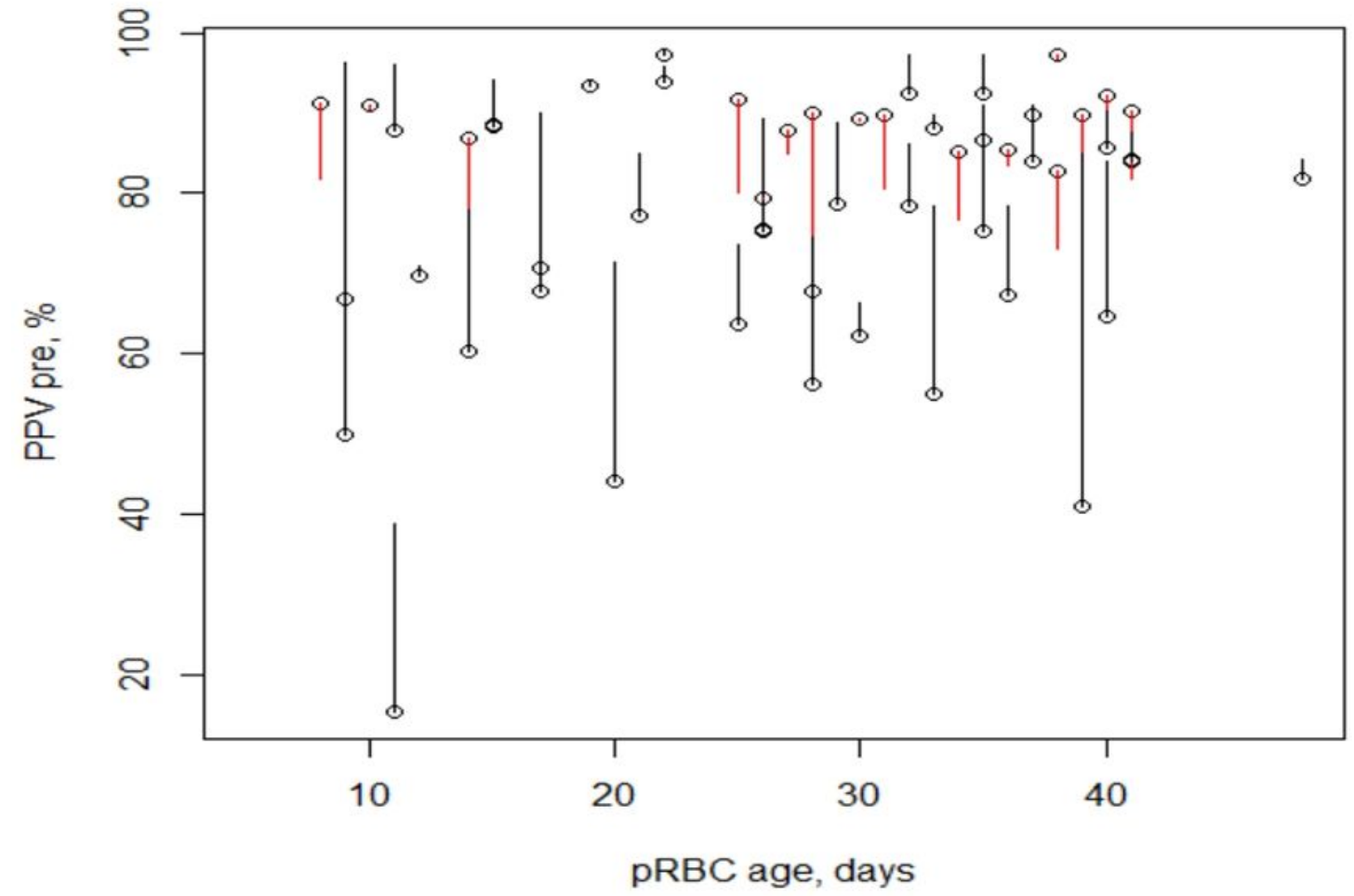

Figure 2

A. $\triangle$ PPV in percent after transfusion of either fresh ( $<14$ days old, $n=9)$, medium $(n=27)$ or relatively old blood ( $>35$ days old, $n=18$ ). B. Correlation of pre-transfusion PPV values and the age of the blood product. The dots indicate the pre-transfusion PPV, the lines the development to post-transfusion. Red lines indicate measurements with a lower, black lines with a higher post-transfusion value. Values in the higher pre PPV range are more likely to develop to a negative $\triangle$ PPV 

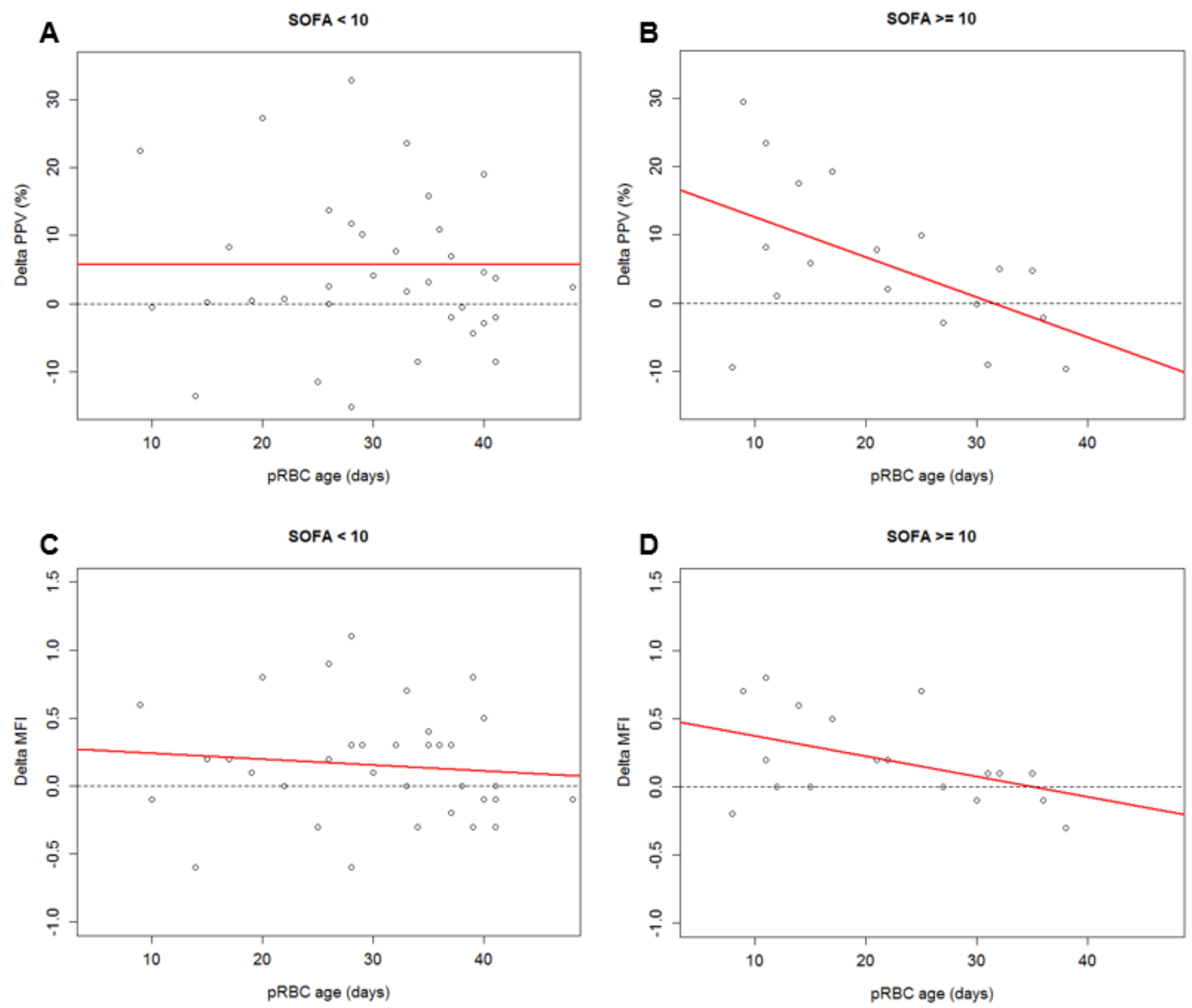

Figure 3

Linear regression model considering $\triangle \mathrm{PPV}(\mathrm{A}, \mathrm{B})$ or $\triangle \mathrm{MFI}(\mathrm{C}, \mathrm{D})$ and the age of $\mathrm{pRBC}$ in low or high SOFA scores

\section{Supplementary Files}

This is a list of supplementary files associated with this preprint. Click to download.

- Appendix.docx 